\title{
Pilot Scale Hollow Fiber Pervaporation System for Phenol Recycling from Coal to Chemical Wastewater
}

\author{
Yao Jie ${ }^{a, *}$, Zhang Dandan ${ }^{a}$, Cai Chao ${ }^{a}$, Guo Hongxiab, Han Bangjun ${ }^{c}$, Han Yahong ${ }^{a}$, \\ Gu Zhenao ${ }^{a}$, Yang Shuren ${ }^{a}$, You Hong ${ }^{a}$, Du Ziwei ${ }^{a}$, Sjack van Agtmaal ${ }^{d}$ and Feng Chunhuid \\ ${ }^{a}$ School of Municipal and Environmental Engineering, Harbin Institute of Technology, P. R. China \\ ${ }^{b}$ Henan Mechanical \& Electrical Engineering College, Xinxiang, Henan, P.R. China \\ ${ }^{c}$ School of Civil Engineering, Heilongjiang University, Xuefu Road, Harbin150090, P.R. China \\ ${ }^{d}$ Evides Industriewater B.V. Schaardijk 150, 3063 NH Rotterdam, The Netherlands
}

\begin{abstract}
Polydimethylsiloxane (PDMS)/Polyvinylidene fluoride (PVDF) hollow fiber composite membrane was prepared by dynamic negative pressure method to treat coal to chemical wastewater containing high concentration of phenol, in which PVDF hollow fiber membrane acts as base membrane and PDMS as modified membrane. In the pilot scale experiment, the influence of aeration rate, temperature, flow rate, pressure under membrane on phenol removal efficiency were investigated and operating parameter optimized. At temperature $70^{\circ} \mathrm{C}$, flow rate of $150 \mathrm{~L} / \mathrm{h}$, pressure under membrane $5 \mathrm{KPa}$, gas-water ratio $0.3,75 \mathrm{~L}$ coal to chemical wastewater containing phenol fluctuated between 1600 and $1800 \mathrm{mg} / \mathrm{L}$ was treated for $6 \mathrm{~h}$, and phenol removal efficiency reached $72 \%$. The system ran stably for $120 \mathrm{~h}$ and performed well, phenol removal efficiency being kept more than $60 \%$.
\end{abstract}

Keywords: Hollow fiber composite membrane, dynamic negative pressure method, pilot scale pervaporation system, coal to chemical wastewater.

\section{INTRODUCTION}

Coal to chemical industries result in a large amount of high concentration organic wastewater, mainly containing phenolic compounds [1], alkane, aromatic hydrocarbons, heterocyclic, ammonia nitrogen and cyanide, hard to be treated by traditional biological treatment [2]. As the unit of preliminary treatment, pervaporation process, with low energy consumption and being environmental friendly, was introduced to recycle phenolic compounds and reduce the biochemical treatment difficulty to achieve resource recycling and improving performance of wastewater treatment .

In comparison with plate-and-frame module, hollow fiber membrane [3-5] illustrates the advantages of highpacking density, self-contained mechanical support, self-contained vacuum channel and economical superiority. In the pilot scale experiment, PDMS/PVDF composite membrane was made by dynamic negative pressure method, and the influence of aeration rate, temperature, flow rate, and pressure under membrane were investigated and optimized.

*Address correspondence to this author at the School of Municipal and Environmental Engineering, Harbin Institute of Technology, Second Campus, Harbin150091, P. R. China; Tel: +86 13904501245;

E-mail:yaojiejie@hotmail.com

\section{EXPERIMENTAL}

\subsection{Materials and Reagents}

PVDF hollow fiber membrane module (pure water flux $1000 \mathrm{~L} / \mathrm{m}^{2} \cdot \mathrm{h}$, work pressure 0.1-0.25 Mpa, membrane area $0.46 \mathrm{~m}^{2}$ ), from SENUO Filtration Technology Co. Ltd.; polydimethylsiloxane (PDMS, molecular weight 6000), from Heowns Biochem Technologies Co. Ltd.; (3-cyanide propyl) triethoxy silane, from Heowns Biochem Technologies Co. Ltd.; dibutyltin dilaurate, from Heowns Biochem Technologies Co. Ltd.; n-hexane, analytically pure, from National Medicine Group Chemical Reagent Co. Ltd. were used.

\subsection{Preparation of Composite Membrane}

PDMS casting solution was prepared by dissolving PDMS, cross-linking agent and catalyst (dibutyltin dilaurate) with mass ratio of 20:3:1 in $n$-hexane with continuous adding of $n$-hexane till concentration of PDMS reaching 20 wt \%, stirred, centrifuged, and deaerated. PVDF membrane was activated by pumping heated $\mathrm{NaOH}$ solution $\left(65^{\circ} \mathrm{C}\right.$, concentration $\left.2 \mathrm{~mol} / \mathrm{L}\right)$ into hollow fiber membrane for $15 \mathrm{~min}$, then rinsing the membrane with deionized water till the effluent water $\mathrm{pH}$ being neutral. Composite membranes were prepared by a dynamic negative pressure coating method, shown in Figure 1, in which peristaltic pump 


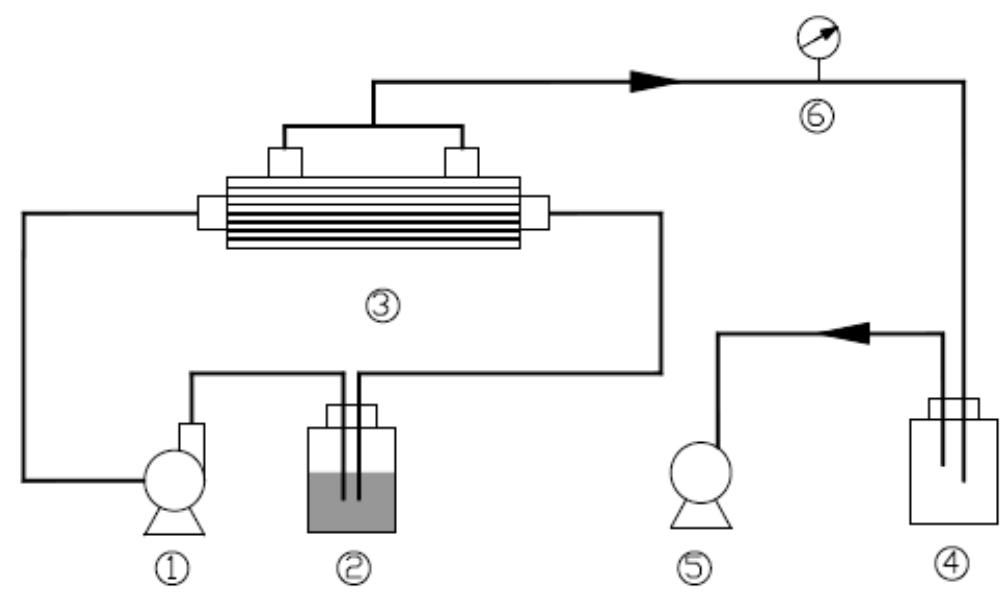

Figure 1: Coating process diagram.

1. Peristaltic pump; 2. Liquid material tank; 3. Hollow fiber membrane module; 4. Buffer bottle; 5 . Vacuum pump; 6 . Vacuum gauge.

was used to pump PDMS casting solution into hollow fiber module, and the flow direction of casting solution varied every $10 \mathrm{~min}$. Certain negative pressure $(0.06$ $\mathrm{MPa}$ ) inside hollow fiber membrane shell was generated with vacuum pump to form a composite layer after $40 \mathrm{~min}$ and cross-link last for $48 \mathrm{~h}$ in $30^{\circ} \mathrm{C}$ till the membrane dried.

\subsection{Pervaporation Test}

The characteristics of wastewater, from Qitaihe Baotailong Coal to Chemical Co. Ltd, were shown in Table 1, which mainly contain phenol, cresol, benzodiazepines, and heterocyclic compounds. The pilot scale pervaporation setup was shown in Figure 2, in which coal to chemical wastewater was pumped into the membrane reaction tank, and the treated water recycled back to wastewater storage tank. In membrane reaction tank, organic substance in wastewater was pervaporated into gas phase through membrane because of the negative pressure made by vacuum pump, then cooled and collected.

The operating parameter was shown in Table 2, determined by Simple Variable Method, in which the

Table 1: Characteristics of Coal to Chemical Wastewater

\begin{tabular}{|c|c|c|c|}
\hline Items & Value & Items & Value \\
\hline \hline $\mathrm{COD}$ & $13000-15000 \mathrm{mg} / \mathrm{L}$ & $\mathrm{SS}$ & $580-650 \mathrm{mg} / \mathrm{L}$ \\
\hline $\mathrm{pH}$ & $7.5-8.1$ & Color & Brown yellow \\
\hline Phenol concentration & $1600-1800 \mathrm{mg} / \mathrm{L}$ & Temperature & $70-80^{\circ} \mathrm{C}$ \\
\hline
\end{tabular}

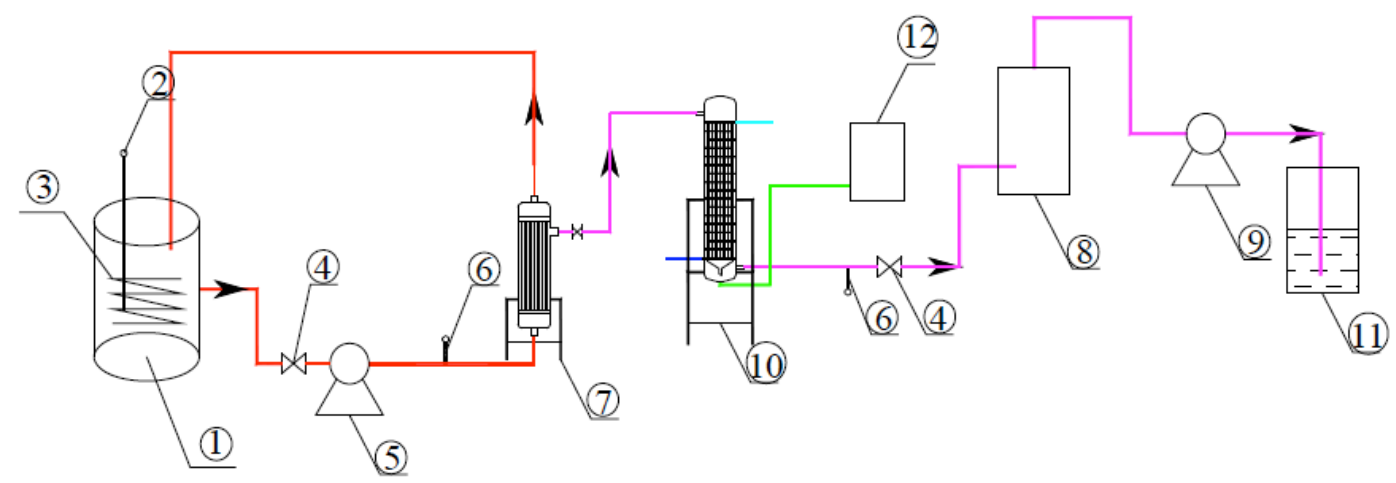

Figure 2: Pervaporation process.

1. Wastewater storage tank; 2.Thermometer; 3 Heater; 4. Valve; 5. Peristaltic pump; 6 . Pressure gauge; 7 . The membrane reaction tank; 8. Buffer tank; 9. Vacuum pump; 10. Condenser; 11. Absorption bottle; 12. Condensate collecting bottles. 
Table 2: Operating Parameters

\begin{tabular}{|c|c|c|c|}
\hline Operating parameter & & Operating parameter \\
\hline \hline Feed volume & $75 \mathrm{~L}$ & Cycle length & $6 \mathrm{~h}$ \\
\hline Aeration rate & 0.3 (gas-water ratio) & Temperature & $70^{\circ} \mathrm{C}$ \\
\hline Flow rate & $150 \mathrm{~L} / \mathrm{h}$ & Pressure under membrane & $5 \mathrm{KPa}$ \\
\hline
\end{tabular}

operating condition of system was evaluated by phenol removal efficiency.

\section{RESULTS AND DISCUSSION}

\subsection{Determination of Operation Parameter}

\subsubsection{Determination of Cycle Length}

Figure 3 showed that with the increase of time, phenol removal efficiency increased while phenol flux decreased. Because the removal of phenol resulted in smaller concentration difference between two sides of the membrane, the mass transfer impetus weakened and phenol flux decreased. After $6 \mathrm{~h}$, the phenol concentration reached $476 \mathrm{mg} / \mathrm{L}$ and phenol removal efficiency $72 \%$; and while $10 \mathrm{~h}$, the phenol concentration $380 \mathrm{mg} / \mathrm{L}$, the efficiency reached $78 \%$. And it could be found that the operation from $6 \mathrm{~h}$ to $10 \mathrm{~h}$ only enhances phenol removal efficiency $6 \%$, so from the view of economics, the operation time was fixed at $6 h$.

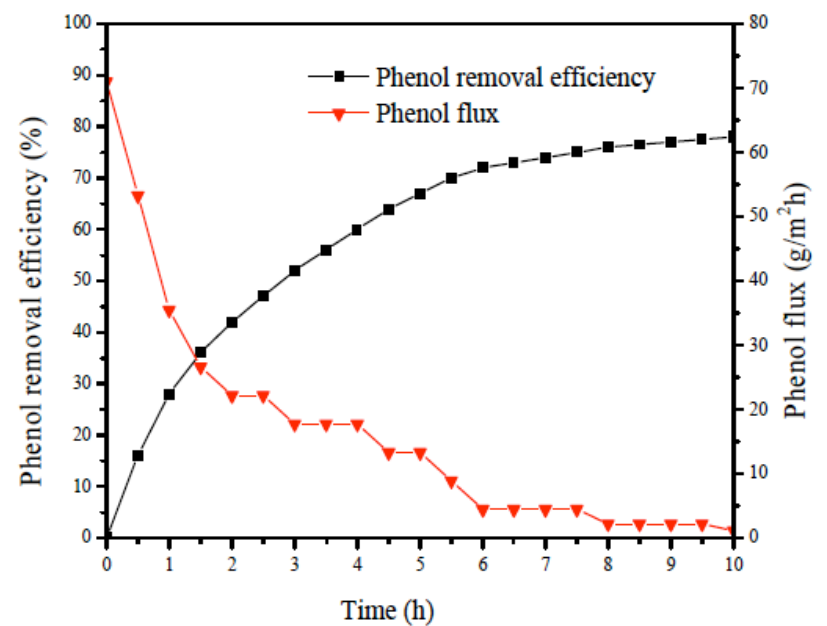

Figure 3: Relationship of phenol removal efficiency and phenol flux with time.

\subsubsection{Determination of Aeration Rate}

The Figure 4 showed that with the enhancement of gas-water ratio, phenol removal efficiency increased, because the aeration created bubbles in the water, which could improve the degree of turbulence in the liquid phase, compress boundary layer on the surface of the membrane, weaken the concentration polarization phenomenon, and reduce the mass transfer resistance. At the same time, aeration could reduce the solubility of phenol in wastewater and make phenol easy to escape from wastewater. When the gas water ratio reaches 0.3 , continuous aeration could not improve removal efficiency effectively, and so gas water ratio of 0.3 be fixed.

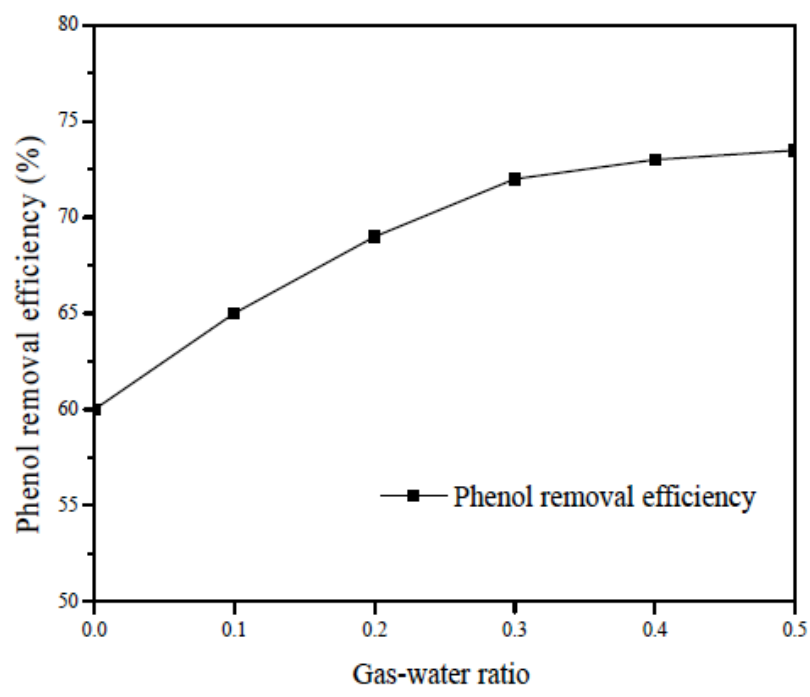

Figure 4: Relationship of phenol removal efficiency with aeration rate.

\subsubsection{Determination of Temperature}

The Figure 5 tells that the elevation of temperature from $55^{\circ} \mathrm{C}$ to $70^{\circ} \mathrm{C}$, phenol removal efficiency increased from $49 \%$ to $72 \%$, because the higher the temperature, the higher phenol molecular energy, which make phenol easy to permeate the membrane and improve phenol removal efficiency. When temperature was $75^{\circ} \mathrm{C}$, the removal efficiency reached $78 \%$, but long time operation at high temperature would cause inconvertible damage for composite membrane, as surface breakage which result in membrane life shorted.

\subsubsection{Determination of Flow Rate}

The Figure 6 showed that with the increase of flow rate, phenol removal efficiency increased, and it is 


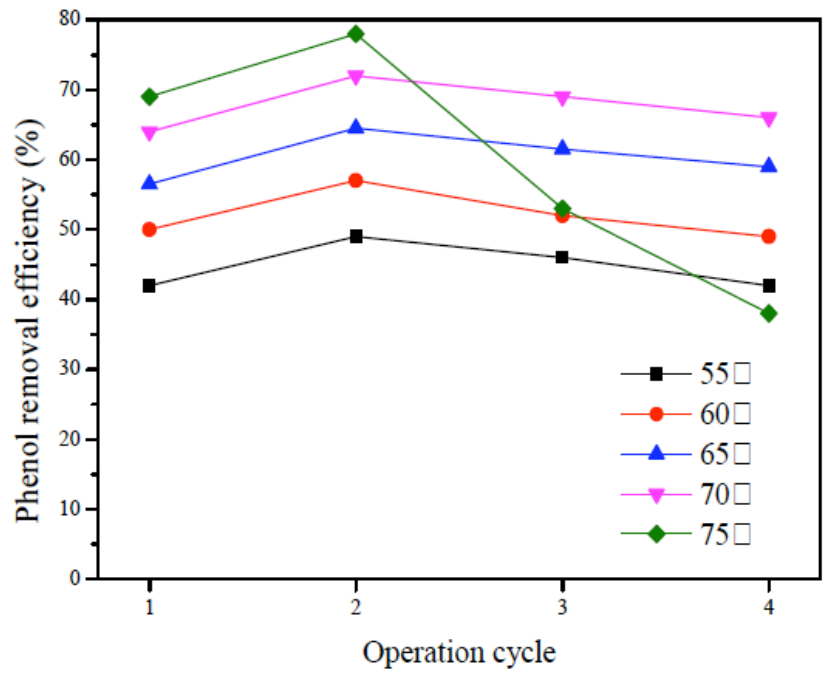

Figure 5: Relationship of phenol removal efficiency with temperature.

found that the influence on phenol removal efficiency is same as aeration, high flow rate accelerate the degree of turbulence in the liquid phase, compressed boundary layer on the surface of the membrane, weakened the concentration polarization phenomenon, reduced the mass transfer resistance. High flow rate had inhibitory effect on membrane fouling, high speed wastewater scour separation membrane surface and made SS, oil hard to adhere membrane surface. While flow rate increased from $150 \mathrm{~L} / \mathrm{h}$ to $210 \mathrm{~L} / \mathrm{h}$, there is limited phenol removal efficiency increase.

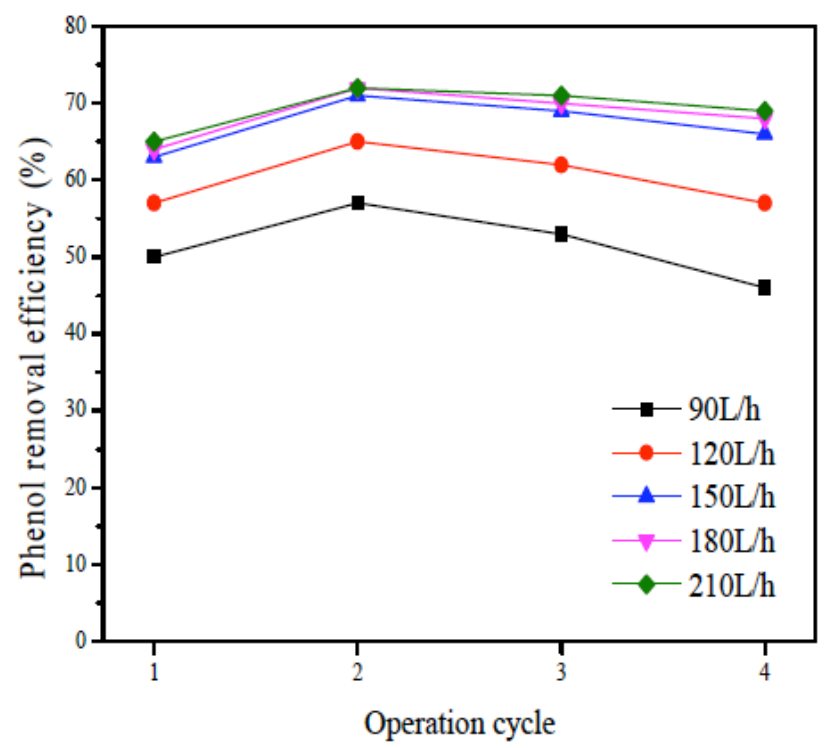

Figure 6: Relationship of phenol removal efficiency with flow rate.

\subsubsection{Determination of Pressure Under Membrane}

From Figure 7 it is found that with the decrease of pressure under membrane, phenol removal efficiency increased, because the lower pressure under membrane, the bigger steam partial pressure concentration difference between two sides of the membrane. The mass transfer impetus increased and promoted phenol permeation, and at low pressure under membrane there is an acceleration for membrane fouling, because whenever pressure is lower, contaminating substance is more inclined to axial movement and adhere to membrane surface. It's important to ensure system sealing and keep pressure under $5 \mathrm{kpa}$ for stable operation.

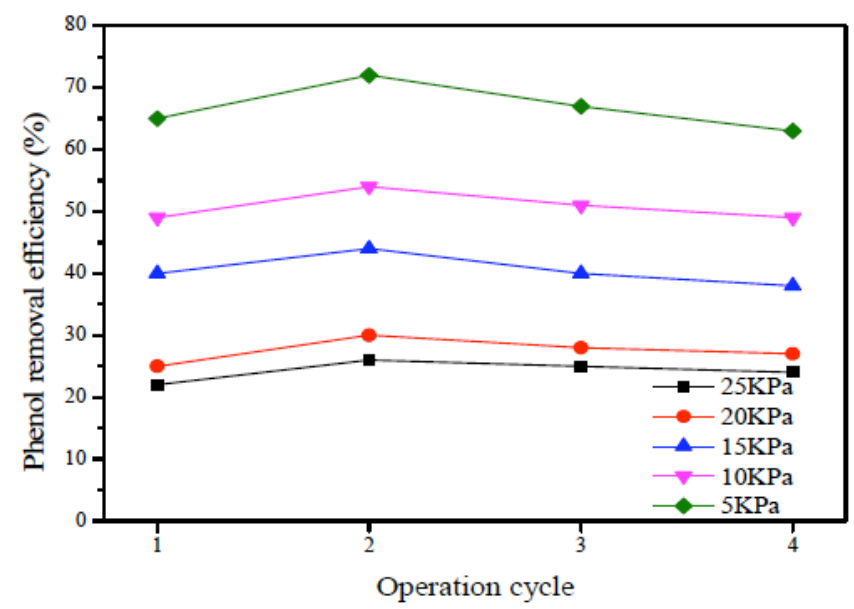

Figure 7: Relationship of phenol removal efficiency with pressure under membrane.

\subsection{Membrane Clean}

Whenever the pervaporation membrane system appear the following situations, such as phenol flux less than 15\%; phenol removal efficiency less than $15 \%$; or obvious membrane fouling, membrane clean is required to restore performance. Membrane cleaning steps includes the following: pumping deionized water to flush the membrane module for $10 \mathrm{~min}$; pumping 4 kinds of liquid, such as deionized water, $0.5 w t \% \mathrm{HCl}$ solutions, $0.5 w t \% \mathrm{NaOH}$ solutions, and $0.5 w t \%$ surfactant solution, to flush the membrane module for $15 \mathrm{~min}$, and pumping deionized water to rinse the residual liquid. The performance of membrane clean method was evaluated by phenol removal efficiency, as shown in Table 3.

From Table 3, the performance of system was recovered after membrane clean, in which surfactant clean performed the best, because PDMS material had a strong affinity for organic pollutant and so oil contamination adhered to membrane and blocked, which could be removed by surfactant clean, and at the same time, surfactant brought bubbles into liquid, flushed SS which adhere to membrane surface. 
Table 3: Membrane Clean and Performance

\begin{tabular}{|c|c|c|c|}
\hline Membrane clean method & Before clean & After clean & Performance improvement \\
\hline \hline Deionized water clean & $57.8 \%$ & $60.2 \%$ & $4.2 \%$ \\
\hline $\mathrm{HCl}$ clean & $57.2 \%$ & $63.5 \%$ & $11.0 \%$ \\
\hline $\mathrm{NaOH}$ clean & $56.8 \%$ & $62.7 \%$ & $10.4 \%$ \\
\hline Surfactant clean & $57.3 \%$ & $69.6 \%$ & $21.5 \%$ \\
\hline
\end{tabular}

\subsection{Continuous Operation Stability of Pervaporation System}

Figures 8 and 9 illustrate that the pervaporation system need about 2 cycles ( $12 \mathrm{~h}$ ) to adjust new coal to chemical wastewater and after 2 cycles, system

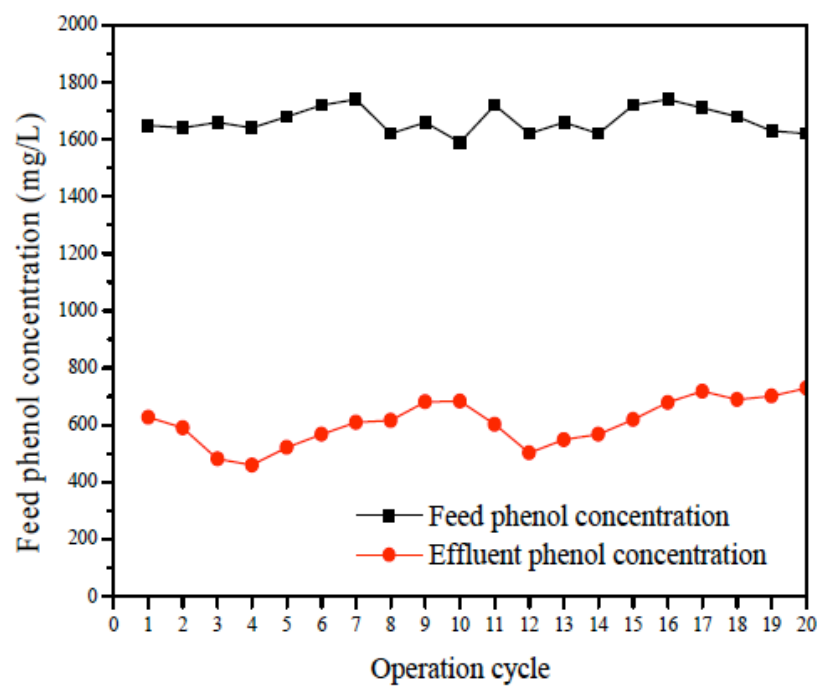

Figure 8: Relationship of phenol feed/effluent concentration with operation cycle.

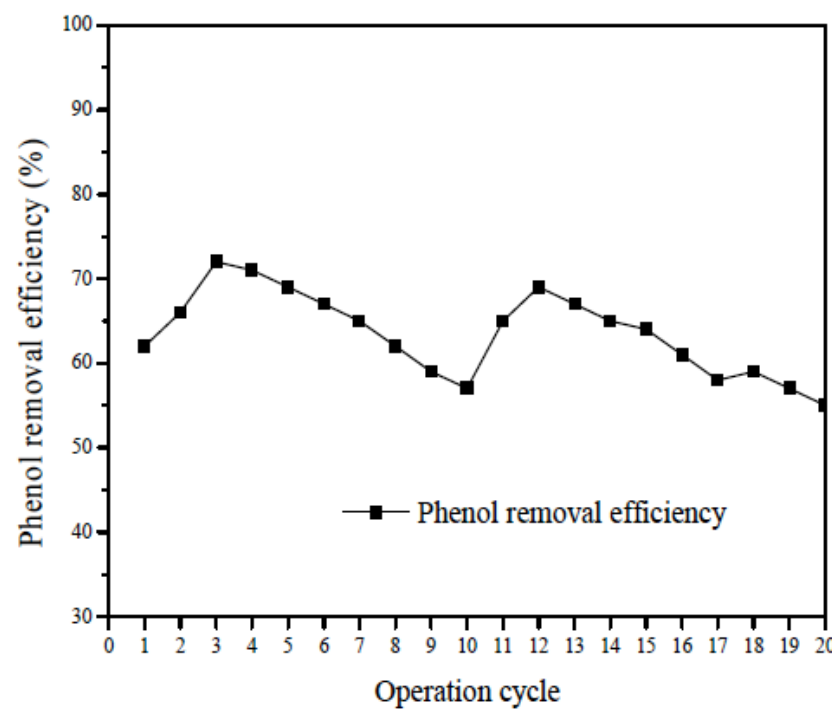

Figure 9: Relationship of phenol removal efficiency with operation cycle. pervaporation performance appears the best, the phenol removal efficiency reaching $72 \%$, then phenol removal efficiency beginning to decrease because of membrane fouling, and after 10 cycles $(60 \mathrm{~h})$, phenol removal efficiency dropped to $57 \%$, system needing to be cleaned to recover performance. When feed phenol concentration fluctuated between 1600 and $1800 \mathrm{mg} / \mathrm{L}$, the system ran stably for $120 \mathrm{~h}$ and performed well, effluent phenol concentration ranging from 400 to 600 $\mathrm{mg} / \mathrm{L}$, phenol removal efficiency kept more than $60 \%$.

\section{CONCLUSIONS}

It could be generated that at temperature $70^{\circ} \mathrm{C}$, the flow rate of $150 \mathrm{~L} / \mathrm{h}$, pressure under membrane $5 \mathrm{KPa}$, gas-water ratio $0.3,75 \mathrm{~L}$ coal to chemical wastewater was treated for $6 \mathrm{~h}$, phenol removal efficiency reached $72 \%$. The performance of system recovered after membrane clean, in which surfactant clean performed best, and performance improvement reach $21.5 \%$. The system ran stably for $120 \mathrm{~h}$ and performed well, as feed phenol concentration fluctuated between 1600 and $1800 \mathrm{mg} / \mathrm{L}$, effluent phenol concentration ranging from 400 to $600 \mathrm{mg} / \mathrm{L}$, and phenol removal efficiency kept more than $60 \%$.

\section{REFERENCE}

[1] Nabholz JV. Environmental hazard and risk assessment under the United States toxic substances control act. J Sci Total Environ 1991; 109: 649-65.

http://dx.doi.org/10.1016/0048-9697(91)90218-4

[2] Yang C, Qian Y, Zhang L, et al. Solvent extraction process development and on-site trial-plant for phenol removal from industrial coal-gasification wastewater. J Chem Eng J 2006; 117: $179-85$.

http://dx.doi.org/10.1016/j.cej.2005.12.011

[3] Athayde AL, Baker RW, Daniels R, et al. Pervaporation for wastewater treatment. J Chentech 1997; 1: 34-9. http://www.osti.gov/energycitations/product.biblio.jsp?osti_id= 438874

[4] Zhang G, Song X, Ji S, et al. Self-assembly of inner skin hollow fiber polyelectrolyte multilayer membranes by a dynamic negative pressure layer-by-layer technique. $\mathrm{J} \mathrm{J}$ Membr Sci 2008; 325: 109-16.

http://dx.doi.org/10.1016/j.memsci.2008.07.016 
[5] Tsai H-A, Chen W-H, Kuo C-Y, et al. Study on the pervaporation performance and long-term stability of aqueous iso-propanol through chitosan/

polyacrylonitrile hollow fiber membrane J. Journal of Membrane Science 2008; 309: 146-55.

http://dx.doi.org/10.1016/j.memsci.2007.10.018

DOI: http://dx.doi.org/10.6000/1929-6037.2014.03.01.4

(c) 2014 Jie et al.; Licensee Lifescience Global.

This is an open access article licensed under the terms of the Creative Commons Attribution Non-Commercial License (http://creativecommons.org/licenses/by-nc/3.0/) which permits unrestricted, non-commercial use, distribution and reproduction in any medium, provided the work is properly cited. 